\title{
Pertussis vaccine in pregnant women: safety and uptake
}

\author{
This article was published in the following Dove Press journal: \\ Vaccine: Development and Therapy \\ 9 March 2016 \\ Number of times this article has been viewed
}

\section{Flor M Munoz \\ Department of Pediatrics, Section of Infectious Diseases, Baylor College of Medicine, Houston, TX, USA}

Correspondence: Flor Munoz Department of Pediatrics, Section of Infectious Diseases, Baylor College of Medicine, One Baylor Plaza, BCM-280, Houston, TX 77030, USA

Tel + I 7I3 7985248

Fax +I 7137986802

Email florm@bcm.edu
Abstract: Pertussis continues to be an important cause of morbidity and mortality in children worldwide, particularly among infants too young to be vaccinated or who are unvaccinated and unprotected by naturally acquired passive antibodies from their mothers. Vaccination of women during pregnancy with an adult formulation of acellular pertussis vaccine in combination with tetanus and diphtheria toxoids (Tdap [tetanus, reduced diphtheria and acellular pertussis vaccine]) is recommended in several industrialized countries to boost the levels of maternal antibodies that are transferred transplacentally and protect infants during the period of life when they are more likely to succumb to pertussis. Data from clinical and epidemiologic studies are supportive of the safety and effectiveness of maternal immunization with pertussis vaccines. Tdap is safe and well tolerated in pregnant women. Local and systemic reactogenicity is similar to that observed in nonpregnant adults, and no serious adverse events have been attributed to Tdap vaccination during pregnancy. Maternal antibodies elicited by the vaccine are efficiently transferred to the fetus through the placenta, and studies have consistently found that infants born to vaccinated mothers have significantly higher concentrations of pertussis antibodies than infants of nonvaccinated mothers. Although a correlate of protection against pertussis is unknown, higher concentrations of antibodies are likely to result in protection of young infants. A reduction in infant pertussis has been shown to occur when high vaccine coverage rates are achieved by pregnant women, as reported in the UK vaccination program. Furthermore, as more vaccine programs incorporate Tdap vaccination during pregnancy, prospective and epidemiologic data will be available to continuously assess the safety and efficacy of this intervention. Improving the uptake of pertussis vaccine among pregnant women remains a challenge that will require the joint effort of multiple stakeholders to improve education, access, and acceptability of the vaccine among pregnant mothers and providers.

Keywords: pertussis, vaccine, pregnancy, maternal immunization, safety, uptake

\section{Introduction}

Pertussis (whooping cough), a vaccine-preventable disease, is among the top ten causes of death among infants and young children worldwide. ${ }^{1-3}$ With millions of patients affected by the illness, the World Health Organization (WHO) estimated in 2008 that up to 195,000 deaths were associated with pertussis in children younger than 5 years of age every year. ${ }^{1}$ More recent estimates from the WHO's Maternal and Child Epidemiology Estimation (MCEE) group and the GBD Study continue to place pertussis among the top causes of childhood mortality, resulting in an estimated 60,000 deaths in children 1 to 59 months of age annually (range 43,000-94,000 and $21,000-127,000$, respectively). ${ }^{2,3}$ While the burden of disease and mortality are likely 
greater in the developing world, pertussis remains a public health threat even in countries with high vaccination coverage rates. ${ }^{4}$ Globally, most pertussis deaths continue to occur in infants who are unvaccinated, or too young to be vaccinated, usually in the first 6 months of life. ${ }^{4,5}$

There are two types of pertussis vaccines: whole cell pertussis (wP) vaccines prepared from killed Bordetella pertussis bacteria of different strains utilizing different methods for inactivation depending on the manufacturer, and acellular pertussis (aP) vaccines prepared from highly purified antigenic components of $B$. pertussis, which vary in type and concentration depending on the manufacturer as well. The components of aP vaccines typically include pertussis toxin (PT), pertactin (PRN), filamentous hemagglutinin (FHA) and fimbriae (FIM) type 2 or 3 proteins. Both wP and aP vaccines used for pediatric immunization are combined with tetanus and diphtheria toxoids (DTPw [diptheria, tetanus, and whole cell pertussis vaccine] or DTaP [diphtheria, tetanus, and acellular pertussis vaccine]), or with other vaccine antigens, and, at this time, are not available as pertussis-only monocomponent vaccines. Combination tetanus vaccines with reduced doses of diphtheria and pertussis components (Tdap [tetanus, reduced diphtheria and acellular pertussis vaccine]), to decrease reactogenicity, are available for use in adolescents and adults to boost antibody concentrations.

\section{Vaccination programs currently in use to provide protection against pertussis}

Pertussis vaccines (DTPw) introduced in the 1940s and utilized as part of the WHO's Expanded Program on Immunization (EPI) since the 1970s resulted in a significant reduction in the incidence and mortality of pertussis in children. ${ }^{4} \mathrm{DTaP}$, a less reactogenic acellular pertussis vaccine, was introduced to the pediatric immunization schedule in the 1990s in several industrialized countries. A resurgence of cases of pertussis and infant mortality ensued, attributed in part to waning immunity and a relatively shorter term protection provided by acellular vaccines. A recent WHO report determined that among 19 countries reporting a resurgence of pertussis, the majority were seeing the results of natural cyclic pertussis epidemics paired with enhanced surveillance afforded by more sensitive polymerase chain reaction (PCR) diagnostic testing and increased awareness of the disease, while five countries experienced a true resurgence, namely the USA, the UK, Australia, Portugal, and Chile. ${ }^{4}$ Interestingly, all countries except Chile utilize aP vaccines for infant immunization. In the case of Chile and possibly other countries where wP vaccine is utilized, it is believed that increased reporting and decreased vaccine coverage explain the increase in pertussis. ${ }^{4}$ In countries where aP vaccine was utilized exclusively, cases of pertussis began to occur more frequently in adolescents and young adults, whose main role has been identified as reservoirs of $B$. pertussis and sources of transmission to infants too young to be vaccinated. ${ }^{6,7}$ The pertussis immunization schedule required adjustments to include a booster dose of Tdap vaccine in adolescents and adults in the USA in $2006 .{ }^{8}$ Despite prompt adoption of the adolescent booster dose and adequate vaccine uptake in this population, pertussis cases continued to increase reaching numbers not seen in over 40 years, as did infant mortality, during large outbreaks reported in the USA in the last decade. ${ }^{4}$ By 2008 , a recommendation to vaccinate women immediately after giving birth as well as household contacts of newborns was instituted, in an attempt to provide protection to infants by preventing pertussis in their mothers and close contacts. ${ }^{9}$ However, ongoing outbreaks and rising incidence of pertussis eventually resulted in the 2012 recommendation by the Advisory Committee on Immunization Practices (ACIP) of the Centers for Disease Control and Prevention (CDC) to immunize all pregnant women with Tdap, regardless of their previous vaccination history..$^{10}$ Vaccination of pregnant women was considered to be the most direct method of protection for newborns and infants in the first few months of life, through passive transfer of maternal antibody after administration of Tdap in the second or third trimester of gestation. Parallel epidemiologic observations and disease burden lead to a similar recommendation by the Department of Health in the UK in 2012, as a temporary outbreak response measure, and in certain high-risk situations (such as outbreaks) or regions of other countries such as Canada, Belgium, Australia, New Zealand, Israel, and Argentina, where maternal immunization with Tdap has been adopted to protect newborns from pertussis. ${ }^{4,11-13}$ The current pertussis immunization strategies recommended by ACIP in the USA, by the UK, and by WHO are shown in Table 1 .

\section{Benefits and risks associated with pertussis vaccine during pregnancy}

It is important to note that recommendations for vaccination of pregnant women against pertussis were not based on data obtained from traditional large prospective randomized, placebo-controlled clinical trials. Pertussis immunization recommendations were adapted to include pregnant women in response to the high burden of disease and in infants too young to be vaccinated in countries that adopted this disease prevention strategy. In the USA and in the UK, large 
Table I Immunization schedules for the prevention of pertussis

\begin{tabular}{|c|c|c|c|}
\hline Target population & $\begin{array}{l}\text { USA } \\
\text { ACIP/CDC }\end{array}$ & UK & WHO \\
\hline $\begin{array}{l}\text { Primary childhood } \\
\text { series }\end{array}$ & $\begin{array}{l}\text { DTaP } \\
2 \text { months } \\
4 \text { months } \\
6 \text { months } \\
12-18 \text { months } \\
4-6 \text { years }\end{array}$ & $\begin{array}{l}\mathrm{DTaP} \\
2 \text { months } \\
3 \text { months } \\
4 \text { months } \\
3-6 \text { years }\end{array}$ & $\begin{array}{l}\text { DTPw } \\
6 \text { weeks } \\
\text { 10-14 weeks } \\
\text { I4-18 weeks } \\
\text { I-6 years }\end{array}$ \\
\hline Adolescent & $\begin{array}{l}\text { Tdap } \\
\text { II-12 years } \\
\text { (up to } 18 \text { years catch up) }\end{array}$ & Not recommended & Not recommended \\
\hline Adults & $\begin{array}{l}\text { Tdap } \\
\text { One dose at any age, including } \\
\text { persons over } 65 \text { years of age }\end{array}$ & Not recommended & Not recommended \\
\hline Pregnant women & $\begin{array}{l}\text { Tdap } \\
\text { One dose at every pregnancy } \\
\text { given at } 27-36 \text { weeks of } \\
\text { gestation* }\end{array}$ & $\begin{array}{l}\text { Tdap } \\
\text { One dose at every pregnancy } \\
\text { at } 28-32 \text { weeks of gestation } \\
\text { (up to } 38 \text { weeks) }\end{array}$ & Not recommended \\
\hline Other & $\begin{array}{l}\text { Tdap } \\
\text { Health care personnel } \\
\text { Contacts of infants }\end{array}$ & Not recommended & $\begin{array}{l}\text { Tdap } \\
\text { Health care personnel in countries with } \\
\text { demonstrated high rates of nosocomial } \\
\text { transmission }\end{array}$ \\
\hline
\end{tabular}

Notes: *Tdap should be administered postpartum in women who were not vaccinated during pregnancy. Breastfeeding is not a contraindication to vaccination. UK immunization schedule: http://www.nhs.uk/conditions/vaccinations/pages/vaccination-schedule-age-checklist.aspx.

Abbreviations: ACIP, Advisory Committee on Immunization Practices; CDC, Centers for Disease Control and Prevention; DTaP, diphtheria, tetanus, and acellular pertussis vaccine; DTPw, diptheria, tetanus, and whole cell pertussis vaccine; Tdap, tetanus, reduced diphtheria and acellular pertussis vaccine; WHO, World Health Organization.

outbreaks of pertussis occurred prior to 2012, despite the use of adolescent and postpartum Tdap vaccination in the USA, prompting the need for new prevention strategies. ${ }^{10,11}$ Although pertussis vaccines are not specifically licensed for pregnant women, licensed vaccines can be administered during pregnancy when women or their fetus are at risk of exposure to an infection that poses a special risk to the mother or the infants, and vaccines that are safe and effective are available for use. ${ }^{14}$ Available epidemiologic data is supportive of the safety ofTdap vaccine in pregnancy, as are the results of several recent clinical trials. Furthermore, the UK experience provides reassuring results from a large population-based safety and efficacy surveillance system. Overall benefits and potential risks are summarized in Table 2.

Initial reports of the use of Tdap in pregnancy confirmed the adequate immune response of pregnant women to the vaccine and the efficient transplacental passage of antibodies to the infant. In an observational study conducted from October 2008 to December 2009 in an obstetric clinic at the University of Louisville, Gall et al compared 52 women who received Tdap in the second trimester of gestation and 52 unvaccinated mothers using recovered maternal and cord blood samples and showed that vaccinated mothers and their infants had significantly higher concentrations of antibodies to all pertussis vaccine antigens; transplacental transfer of antibody was efficient; and the odds of the infant being protected by PT, diphtheria, and tetanus antibodies were higher when mothers were vaccinated antepartum. The study reported that there were no adverse events to the vaccine. ${ }^{15}$ Similarly, in an observational cohort study conducted during a pseudo-outbreak of pertussis at Darmouth-Hitchcock Medical Center, in New Hampshire, Hardy-Fairbanks et al followed a convenience sample of 16 women who received Tdap during pregnancy (any trimester) in 2006 and compared them to 54 unvaccinated pregnant women who delivered between March 2008 and February 2009. ${ }^{16}$ Although there was no mention of adverse outcomes, in this serological study (maternal - cord - infant), Tdap vaccination during pregnancy enhanced infant antibody concentrations against pertussis in the first months of life. At 7 months of age, after the primary series of infant vaccines, antibody concentrations to pertussis antigens (PT, FHA, PRN, but not FIM) were lower in infants born to mothers who were vaccinated during pregnancy, but this difference did not persist after booster immunization.

A multicenter, randomized, double blind, placebocontrolled clinical trial of Tdap in pregnancy was conducted in the USA from 2009 to $2012 .{ }^{17}$ Forty eight health women were randomized at a 2:1 ratio to receive Tdap or placebo injection during pregnancy $(n=33)$ or crossover Tdap vaccination 
Table 2 Potential benefits and risks of pertussis vaccination during pregnancy

\begin{tabular}{|c|c|c|}
\hline Target population & Potential benefits & Potential risks \\
\hline $\begin{array}{l}\text { Maternal immunization } \\
\text { in general }\end{array}$ & $\begin{array}{l}\text { Mothers are capable of responding to vaccine antigens } \\
\text { and achieve antibody concentrations similar to those of } \\
\text { nonpregnant adults } \\
\text { Mothers have regular access to medical care and several } \\
\text { opportunities to receive immunizations during pregnancy } \\
\text { Prevention of infection is part of good health maintenance } \\
\text { in a mother and of a healthy pregnancy }\end{array}$ & $\begin{array}{l}\text { Information regarding maternal immunization in general is } \\
\text { based mostly on observational studies, epidemiologic studies, } \\
\text { and small clinical trials. However, surveillance systems are } \\
\text { in place to evaluate the safety of vaccines recommended } \\
\text { in pregnancy, including Tdap, and large clinical trials are in } \\
\text { progress or planned to continue to assess the safety and } \\
\text { effectiveness of maternal immunization with Tdap }\end{array}$ \\
\hline Mother & $\begin{array}{l}\text { Vaccination can prevent pertussis infection in the mother } \\
\text { Prevention of the consequences of infection that may affect } \\
\text { the pregnancy, such as fever, preterm labor, or preterm } \\
\text { delivery, are a result of vaccination }\end{array}$ & $\begin{array}{l}\text { Vaccine safety is important to consider including the risk of: } \\
\text { - Fever } \\
\text { - Systemic reactogenicity } \\
\text { - Allergic/anaphylactic reactions } \\
\text { There are no safety concerns reported to date with the use } \\
\text { of Tdap vaccine in pregnancy }\end{array}$ \\
\hline Fetus & $\begin{array}{l}\text { A healthy mother and pregnancy results in a healthy fetus } \\
\text { that is more likely to grow and complete a term pregnancy } \\
\text { Use of vaccines in the second or third trimester of } \\
\text { gestation minimizes any potential risk of embryotoxicity } \\
\text { or teratogenicity }\end{array}$ & $\begin{array}{l}\text { Use of live vaccines should be avoided given theoretical risk } \\
\text { of infection to the fetus (no live vaccines are currently in use } \\
\text { for pertussis prevention) } \\
\text { There are no theoretical safety concerns with the use of } \\
\text { effective inactivated vaccines during pregnancy }\end{array}$ \\
\hline Newborn and infant & $\begin{array}{l}\text { Transplacental passage of maternal antibodies protects } \\
\text { infants against pertussis infection before they are able to } \\
\text { be immunized } \\
\text { Newborns receive high concentrations of antibodies } \\
\text { when mothers are vaccinated during the second or third } \\
\text { trimester of gestation } \\
\text { The half-life of the passively acquired antibodies is such } \\
\text { that high concentrations are still present at } 2 \text { months of } \\
\text { age, when routine infant vaccination against pertussis begins } \\
\text { Infants may also benefit from breast milk antibodies which } \\
\text { are found in high concentrations after maternal vaccination } \\
\text { Vaccination of women during pregnancy provides the most } \\
\text { direct and efficient protection to newborns and young } \\
\text { infants against pertussis }\end{array}$ & $\begin{array}{l}\text { High levels of maternal antibody may interfere with the } \\
\text { infant's ability to respond to active immunization with high } \\
\text { concentrations of antibody. However, priming with active } \\
\text { immunization is preserved, and infants of mothers who are } \\
\text { vaccinated with Tdap display an adequate booster response } \\
\text { to vaccination }\end{array}$ \\
\hline
\end{tabular}

Abbreviation: Tdap, tetanus, reduced diphtheria and acellular pertussis vaccine.

postpartum ( $\mathrm{n}=15)$, and compared to a control group of 32 nonpregnant women matched by age. Tdap was well tolerated by pregnant women, who experienced a similar reactogenicity profile as postpartum and nonpregnant women, commonly reporting pain at the site of injection $(75.8 \%$ of women vaccinated during pregnancy vs $78.1 \%$ nonpregnant), and low incidence of fever (3\%). Importantly, immune responses to all vaccine antigens were not different in pregnant women when compared to nonpregnant controls, and pertussis antibodies were efficiently transferred transplacentally to the infant. At the time of birth and up to 2 months after delivery, infants had significantly higher concentrations of antibodies to all pertussis antigens compared to infants of nonvaccinated mothers. After the primary series of vaccines, infants of women who received Tdap during pregnancy had lower concentrations of antibodies to all pertussis antigens (only significant for FHA) and diphtheria, but not tetanus; however, these differences disappeared after the infant's 12-month booster DTaP vaccination. The clinical implications of a relatively lower (not always statistically significant or consistent) concentration of vaccine-specific antibodies after the primary series of infant vaccines are unknown. However, the significantly higher concentrations of pertussis antibodies achieved at birth and in the first 2 months of life are likely to result in infant protection against pertussis until the start of active infant immunization. At least three other prospective, randomized clinical studies evaluating Tdap in pregnant women in Canada, Belgium, and Vietnam have been completed. ${ }^{18}$

The safety of Tdap in pregnancy has been assessed by several retrospective database and observational studies. Shakib et al reported no significant differences on the incidence of spontaneous or elective abortion, preterm delivery, gestational age, birth weight, congenital anomalies, or complex medical conditions after birth in a retrospective cohort of 138 women 
who received Tdap during pregnancy (two-thirds in the first trimester of gestation) and their infants and 552 mother-infant pair controls during 2005-2009. ${ }^{19}$ Concurrently, during a time when Tdap was not routinely recommended in pregnancy from 2005 to 2010, the vaccine safety adverse event reporting system (VAERS) did not identify any concerning patterns in maternal, infant, or fetal outcomes among 132 reports of Tdap administered to pregnant women $(77.3 \%$ during the first trimester), and the pregnancy registry for Adacel ${ }^{\mathrm{TM}} \mathrm{did}$ not find increase in the incidence of spontaneous abortion or preterm deliveries among 539 reports of vaccine receipt during pregnancy. ${ }^{20,21}$ An observational cohort study carried out by Kharbanda et al after the 2010 California outbreak used electronic medical record and claims data from seven Vaccine Safety Datalink sites to identify 26,229 women who received Tdap vaccine during pregnancy and compared their outcomes with 97,265 who did not. ${ }^{22}$ Tdap vaccination was not associated with increased risks of adverse birth outcomes in this cohort, specifically preterm birth and small for gestational age (SGA) infant birth, and hypertensive disorders of pregnancy in the mother. A slightly higher incidence of chorioamnionitis was observed in the group of mothers vaccinated during pregnancy compared to the nonvaccinated cohort (6.1\% vs 5.5\%), but this difference was not statistically significant. Finally, the safety report from the UK maternal Tdap vaccination program is consistent with the experience in the USA. Donegan et al followed 20,074 women who received Tdap in the third trimester of pregnancy using the UK Clinical Practice Research Datalink and compared them to a historical unvaccinated control group..$^{23}$ Adverse events reported during pregnancy and delivery were evaluated, with stillbirth as the primary outcome. Investigators did not find an increased risk of stillbirth in the 14 days after vaccination (incidence rate ratio $0.69,95 \%$ confidence interval [CI] $0.23-1.62$ ) or later in pregnancy $(0.85,0.44-1.61)$ compared with historical national rates. There was no evidence that vaccination accelerated the time to delivery, nor of an increased risk of stillbirth, maternal or neonatal death, pre-eclampsia or eclampsia, hemorrhage, fetal distress, uterine rupture, placenta or vasa previa, cesarean delivery, low birth weight, or neonatal renal failure. Congenital anomalies were not sought, but they are being followed through condition-specific registries.

\section{Impact and uptake of pertussis vaccine in pregnant women}

Vaccination during pregnancy is expected to be more effective in reducing the risk of pertussis in young infants than vaccination of the mother postpartum, or cocooning strategies that include the father and one additional caretaker. In study by Terranella et al, pregnancy vaccination with Tdap was estimated to be able to reduce infant pertussis cases by $33 \%$ vs $20 \%$ with postpartum vaccination, infant hospitalizations by $38 \%$ vs $19 \%$, and infant deaths by $49 \%$ vs $16 \%{ }^{24}$ In the USA, postpartum vaccination continues to be recommended for women who do not receive Tdap during pregnancy, as additional benefit in reducing the impact of infant pertussis can be achieved, albeit at a higher cost. ${ }^{24-26}$ Of note, antibody responses after Tdap vaccination in women of childbearing age and postpartum women only begin to increase 5-7 days after immunization, and although they reach peak levels by day 14 after vaccination, this response might not be rapid enough to provide protection to mothers who are vaccinated close to their date of delivery or postpartum, or to their infants who are often exposed shortly after delivery. ${ }^{27}$ Considering that active placental transport of maternal antibody to the fetus occurs predominantly from the 28th week of gestation onward and that vaccination shortly prior to delivery is not likely to allow sufficient time for the transfer of antibodies, the suggested optimal time for Tdap vaccination is in the late second trimester to early in the third trimester. ${ }^{28}$ However, the vaccine can be given at any time during pregnancy and up to delivery.

Pertussis vaccination is recommended with each pregnancy to boost maternal antibody concentrations and ensure maximal protection to every newborn, independently from the number and timing of prior pregnancies. Vaccine-induced pertussis antibodies wane over time and the protective antibody level required in newborn infants or the quality of protection afforded is unknown. Vaccine-induced pertussis antibodies measured in paired maternal and umbilical cord serum show significant decay over a 2 -year interval between pregnancies. ${ }^{29}$ However, pertussis antibody levels in the cord blood of infants whose mothers were vaccinated $\sim 13$ months earlier (following the birth of an older sibling) were found to be significantly higher than those in cord blood of the older sibling prior to maternal vaccination. ${ }^{30}$ Some investigators are currently working on assessing the relative avidity index (RAI) of anti-PT antibodies in maternal and cord sera after maternal immunization with Tdap. ${ }^{31,32}$ Furthermore, the role of cell-mediated immune responses needs to be better understood. Huygen et al have proposed that although Tdap vaccination increases vaccine-specific $\mathrm{IgG}$ antibodies to the same extent in pregnant and nonpregnant women, the stimulation of vaccine-specific Th1 type cellular immune responses appear to be transient and impaired during pregnancy, as only tetanus toxin-specific but not pertussis antigen-specific T-cell responses were elicited in pregnant 
subjects 1 month after vaccination. ${ }^{33}$ Lastly, infant protection through breast milk antibodies is a potential additional benefit from maternal immunization that continues to be studied. ${ }^{34}$

The uptake of Tdap in pregnant women in the USA during the 2010 California outbreak and prior to the 2012 ACIP recommendation to immunize all women during pregnancy varied from $15.9 \%$ to $30 \% .{ }^{22}$ The uptake after the 2012 recommendation has been reported to be similar. A CDC study utilizing the Pregnancy Risk Assessment Monitoring System (PRAMS) provided an estimate median percentage of $55.7 \%$ (range $38.2 \%-76.6 \%$ ) of women with live births receiving Tdap vaccine at some point before, during, or after a live birth in one of 16 states of New York City in the USA in $2011 .{ }^{35}$ Less than $10 \%$ accounted for vaccinations given during pregnancy. In the UK, rapid uptake of vaccine was achieved in the first year after introduction of the Tdap maternal immunization priority program, and rates of greater than $70 \%$ were reported. ${ }^{36}$ High coverage rates have been proven difficult to maintain, even in a system where vaccinations can be provided at no cost to the patient during routine prenatal care. Current estimates of coverage in the UK are just below $60 \%$, and regularly updated data for England are available at https://www.gov.uk/government/collections/vaccineuptake\#pertussis-vaccine-uptake-in-pregnant-women.

Perhaps, the most significant contribution to the efforts of preventing infantile pertussis through maternal immunization has been the efficacy data generated from the UK vaccination program. A vaccine effectiveness of at least $90 \%$ is expected among infants 2-3 months of age when maternal pertussis vaccine is administered at least 7 days or more prior to delivery. This is an effectiveness that is similar to that achieved by active infant vaccination. The UK program is also an important source of data to understand what works and what needs to be improved when implementing a new program of vaccination during pregnancy. While in the USA, prenatal care is provided by obstetricians for the majority of pregnant women, most women in the UK are cared for by general care physicians and midwives, who follow only healthy mothers, not those with complications. Access to the vaccine and to information and a standard recommendation are important elements in the implementation of a maternal vaccination program.

\section{Strategies to promote the uptake of vaccination against pertussis in pregnant women}

A recommendation alone is not sufficient to achieve adequate coverage of vaccines in general, particularly among pregnant women. Patients and providers need a substantial amount of information, education, and support to understand the rationale behind this new vaccination strategy. This is especially true when the target population, pregnant women, is considered to be a vulnerable group who is not usually offered vaccines, with the exception of tetanus toxoid or influenza vaccine, which are used inconsistently in different geographic regions and health systems. Awareness of the current problem of pertussis, its effects on morbidity and mortality in newborns and young infants, and the limitations of the current preventive strategies is an important first step. In general, obstetricians and providers of prenatal and delivery care are less likely to be informed of this primarily pediatric issue; yet, they are the most important resource to the pregnant mother because of the special situation that pertussis infection in early life requires an intervention during pregnancy. In most settings, the recommendation to receive Tdap vaccine during pregnancy is most effective when received by the pregnant mother from her obstetric or prenatal care provider. ${ }^{37}$ In a number of surveys for influenza vaccine, and more recently for Tdap vaccine, most pregnant women would accept the vaccination if offered by their health care provider. ${ }^{37,38}$

Considering the complexity of the decision making processes a mother faces during her pregnancy, it is important that providers are able to establish an efficient communication and a relationship of trust. Most women recognize their vulnerability as well as the intense responsibility they assume when embarking on a pregnancy. Every decision is made in the context of the woman's cultural background, personal beliefs, fears, insecurities, values, and level of education, among other factors. In the current era of instant access to information and also hesitancy for immunizations, women are influenced by information about vaccines they are able to obtain from many sources, some of which will reinforce their skepticism, while some will be supportive. Being aware of these dynamics is important for the health care provider to be able to dedicate the time needed to discuss options and provide continued education to their pregnant patient. An engaged provider will be more valuable than the simple act of sharing facts and results of scientific studies that, although supportive of the safety and efficacy of the vaccine, might be meaningless for a pregnant mother who is concerned with the safety of her child. Once an initial communication has been established, the use of tools such as phone or text reminders, website access, and other methods of continuing education would be appropriate.

Access to the vaccine is the third element of a successful vaccination program. It is clear from the experience with 
influenza vaccination in pregnancy that the highest uptake is achieved when the vaccine is recommended and given at the prenatal care practice, compared to when it is recommended and not offered on site. ${ }^{39}$ This paradigm is anticipated to work also for Tdap, where ideally health care providers will have the vaccine on site at their offices and will be able to administer the vaccination at any time during routine prenatal care visits. The necessary elements to achieve this practice include the establishment of the obstetric/prenatal care office as a vaccine provider site. This can be accomplished through different methods, from having a designated vaccinator and all the appropriate equipment in the clinic, to utilizing multidisciplinary clinic resources including a pharmacy or vaccine clinic that are in the same premises. This is better than relying on the mother to search for a place that would provide her with the vaccination while pregnant, given misconceptions regarding risk and liability concerns. Tools for providers and patients are available from sources such as the CDC and the American Congress of Obstetrics and Gynecology. ${ }^{40}$

\section{Conclusion}

Pertussis is a vaccine-preventable disease that continues to cause significant morbidity and infant mortality worldwide. $\mathrm{wP}$ and aP vaccines are available for the prevention of pertussis in infants starting at 2 months of age through adolescence, while reduced-dose aP vaccines in combination with tetanus toxoid and diphtheria toxoids are recommended for immunization of adults. Vaccination of women during pregnancy is more likely to provide protection to the newborn infant than preconception or postpartum vaccination. Health authorities in several industrialized countries have recommended that women receive Tdap during every pregnancy, independent from previous vaccination or number of pregnancies, in order to provide each newborn with the highest possible concentration of antibodies to pertussis at birth and reduce the risk of early acquisition of pertussis infection, severe disease, and mortality. Tdap vaccine has been shown to be well tolerated and safe in pregnant women. Early studies have demonstrated adequate immune responses to the vaccine antigens in pregnant women, efficient transplacental antibody transfer, and high concentrations of pertussis antibodies in infants of vaccinated mothers that last until the infant's first series of pertussis vaccines begins. A relative reduction in vaccine-specific antibody concentrations after completion of the primary series of immunizations has been reported in infants born to mothers vaccinated with Tdap during pregnancy. However, priming and boost responses remain intact, and infants are likely to benefit due to protection from significantly higher concentrations of pertussis antibodies in the first 2 months of life. Uptake of Tdap vaccine among pregnant women has been less than optimal in countries that have adopted this practice, even when vaccine is provided to pregnant women as part of their routine prenatal care. The most important component of a successful vaccination program for pregnant women hinges on the recommendation from their obstetric or prenatal care provider to receive the vaccine. Engaging in a discussion to explain the reason and need for Tdap immunization during pregnancy, and to discuss the safety and effectiveness information available to date, as well as providing easy access to the vaccine are key elements to improve coverage of pertussis vaccines in pregnancy and protection of infants against pertussis.

\section{Disclosure}

The author has no conflicts of interest to report in relation to this paper.

\section{References}

1. Black RE, Cousens S, Johnson HL; for the Child Health Epidemiology Reference Group of WHO and UNICEF. Global, regional, and national causes of child mortality in 2008: a systematic analysis. Lancet. 2010; 375:1969-1987.

2. Liu L, Oza S, Hogan D, et al. Global, regional, and national causes of child mortality in 2000-13, with projections to inform post-2015 priorities: an updated systematic analysis. Lancet. 2015;385:430-440.

3. GBD 2013. Mortality and Causes of Death Collaborators. Global, regional, and national age-sex specific all-cause and cause-specific mortality for 240 causes of death, 1990-2013: a systematic analysis for the Global Burden of Disease Study 2013. Lancet. 2015;385:117-171.

4. World Health Organization. Pertussis vaccines: WHO position paper. Wkly Epidemiol Rec. 2015;90(35):433-458.

5. Centers for Disease Control and Prevention. 2014 Provisional Pertussis Surveillance Report. Provisional 2014 Reports of Notifiable Diseases, January 9, 2015, Vol 63, No 53. Available from: http://www.cdc.gov/ $\mathrm{mmwr} / \mathrm{preview} / \mathrm{mmwrhtml} / \mathrm{mm} 6353 \mathrm{md} . \mathrm{htm}$ ?s_cid=mm6353md_w. Accessed August 31, 2015

6. Bisgard KM, Pascual FB, Ehresmann KR, et al. Infant pertussis: who was the source? Pediatr Infect Dis J. 2004;23(11):985-989.

7. Wendelboe AM, Njamkepo E, Bourillon A, et al; the Infant Pertussis Study Group. Transmission of Bordetella pertussis to young infants. Pediatr Infect Dis J. 2007;26:293-299.

8. Centers for Disease Control and Prevention, Advisory Committee on Immunization Practices (ACIP). Preventing tetanus, diphtheria, and pertussis among adolescents: use of tetanus toxoid, reduced diphtheria toxoid and acellular pertussis vaccines, recommendations of the ACIP. MMWR Recomm Rep. 2006 ;55(RR-3):1-34.

9. Centers for Disease Control and Prevention, Advisory Committee on Immunization Practices (ACIP). Prevention of pertussis, tetanus, and diphtheria among pregnant and post-partum women and their infants, recommendations of the ACIP. MMWR Recomm Rep. 200857(RR4):1-51. Erratum in: MMWR Morb Mortal Wkly Rep. 2008 July 4;57(26):723.

10. Centers for Disease Control and Prevention, Advisory Committee on Immunization Practices (ACIP). Updated recommendations for use of tetanus toxoid, reduced diphtheria toxoid, and acellular pertussis vaccine (Tdap) in pregnant women - ACIP, 2012. MMWR. 2013;62(7):131-135. 
11. National Health Service. Whooping cough vaccination in pregnancy. Available from: http://www.nhs.uk/conditions/pregnancy-and-baby/ pages/whooping-cough-vaccination-pregnant.aspx Accessed August 31, 2015.

12. Public Health Agency of Canada. Canadian Immunization Guide. Immunization in Pregnancy and Breastfeeding. Available from: http:// www.phac-aspc.gc.ca/publicat/cig-gci/p03-04-eng.php. Accessed August 31, 2015.

13. Australian Government Department of Health. The Australian Immunization Handbook. Updated June 2015. Pertussis. Available from: http://www.immunise.health.gov.au/internet/immunise/publishing. nsf/Content/Handbook10-home handbook10part4 handbook10-4-12 Accessed August 31, 2015.

14. ACOG Committee Opinion No. 566: Update on immunization and pregnancy: tetanus, diphtheria, and pertussis vaccination. Obstet Gynecol. 2013;121(6):1411-1414.

15. Gall SA, Myers J, Pichichero M. Maternal immunization with tetanusdiphtheria-pertussis vaccine: effect on maternal and neonatal serum antibody levels. Am J Obstet Gynecol. 2011;204(4):334.e1-e5.

16. Hardy-Fairbanks AJ, Pan SJ, Decker MD, et al. Immune responses in infants whose mothers received Tdap vaccine during pregnancy. Pediatr Infect Dis J. 2013;32:1257-1260.

17. Munoz FM, Bond NH, Maccato M, et al. Safety and immunogenicity of tetanus diphtheria and acellular pertussis (Tdap) immunization during pregnancy in mothers and infants: a randomized clinical trial. JAMA. 2014;311:1760-1769.

18. Universiteit Antwerpen. Impact of Pertussis Vaccination in Pregnancy on Maternal Protection Offered to Young Infants. Available from: https:// clinicaltrials.gov/ct2/show/study/NCT01698346?view=results. NLM identifier: NCT01698346. Accessed August 31, 2015.

19. Shakib JH, Korgenski K, Shenq X, Varner MW, Pavia AT, Byington CL. Tetanus, diphtheria, acellular pertussis vaccine during pregnancy: pregnancy and infant health outcomes. J Pediatr. 2013;163(5):1422-1426. e1-e4.

20. Zheteyeva YA, Moro PL, Tepper NK, et al. Adverse event reports after tetanus toxoid, reduced diphtheria toxoid, and acellular pertussis vaccines in pregnant women. Am J Obstet Gynecol. 2012;207(1):59. e1-e7.

21. Wang M, et al. Pregnant women receiving tetanus-diphtheria-acellular pertussis (Tdap) vaccine: 6 years of Adacel vaccine pregnancy registry data. Presented at the 27th International Conference on Pharmacoepidemiology and Therapeutic Management, Chicago, IL. Pharmacoepidemiol Drug Saf. 2011;20:S1-S364.

22. Kharbanda EO, Vazquez-Benitez G, Lipkind HS, et al. Evaluation of the association of maternal pertussis vaccination with obstetric events and birth outcomes. JAMA. 2014;312(18):1897-1904.

23. Donegan K, King B, Bryan P. Safety of pertussis vaccination in pregnant women in UK: observational study. BMJ. 2014;349:g4219.

24. Terranella A, Asay GR, Messonnier ML, Clark TA, Lian JL. Pregnancy dose Tdap and postpartum cocooning to prevent infant pertussis: a decision analysis. Pediatrics. 2013;131(6):e1748-e1756.
25. Ding Y, Yeh SH, Mink CA, Zangwill KM, Allred NJ, Hay JW. Costbenefit analysis of hospital based post-partum vaccination with combined post-tetanus toxoid, reduced diphtheria toxoid, and acellular pertussis vaccine (Tdap). Vaccine. 2013;31(22):2558-2564.

26. Quinn HE, Snelling TL, Habig A, et al. Parental Tdap boosters and infant pertussis: a case-control study. Pediatrics. 2014;134:713-720.

27. Halperin BA, Morris A, Mackinnon-Cameron D, et al. Kinetics of the antibody response to tetanus-diphtheria-acellular pertussis vaccine in women of childbearing age and postpartum women. Clin Infect Dis. 2011;53(9):885-892.

28. Englund JA. The influence of maternal immunization on infant immune responses. J Comp Pathol. 2007;137(Suppl 1):S16-S19.

29. Healy CM, Rench MA, Baker CJ. Importance of timing of maternal combined tetanus, diphtheria, and acellular pertussis (Tdap) immunization and protection of young infants. Clin Infect Dis. 2013;56:539-544.

30. Leuridan E, Hens N, Peeters N, de Witte L, Van der Meeren O, Van Damme P. Effect of a pre-pregnancy pertussis booster dose on maternal antibody titers in young infants. Pediatr Infect Dis. 2011;30:608610.

31. Raya BA, Bamberger E, Almog M, Peri R, Srugo I, Kessel A. Immunization of pregnant women against pertussis: the effect of timing on antibody avidity. Vaccine. 2015;33(16):1948-1952.

32. Maertens K, Hoang THT, Cabore RN, Leuridan E. Avidity of maternal pertussis antibodies after vaccination during pregnancy. Vaccine. 2015; 33(42):5489.

33. Huygen K, Cabore RN, Maertens K, Van Damme P, Leuridan E. Humoral and cell mediated immune responses to a pertussis containing vaccine in pregnant and non-pregnant women. Vaccine. 2015;33(33): 4117-4123.

34. Maertens K, Schutter SD, Braeckman T, et al. Breastfeeding after maternal immunization during pregnancy: providing immunological protection to the newborn: a review. Vaccine. 2014;32:1786-1792.

35. Ahluwalia IB, Ding H, D'Angelo D, et al. Tetanus, diphtheria, pertussis vaccination coverage before, during and after pregnancy -16 states and New York City 2011. MMWR Morb Mortal Wkly Rep. 2015; 64(19):522-526.

36. Amirthalingam G, Andrews N, Campbell H, et al. Effectiveness of maternal pertussis vaccination in England: an observational study. Lancet. 2014;384:1521-1528.

37. Donaldson B, Jain P, Holder BS, Lindsay B, Regan L, Kampmann B. What determines the update of pertussis vaccine in pregnancy? A cross sectional survey in an ethnically diverse population of pregnant women in London. Vaccine. 2015;33(43):5822-5828.

38. Mak D, Regan AK, Joyce S, et al. Antenatal care provider's advice is the key determinant of influenza vaccination in pregnant women. Aust N Z J Obstet Gynaecol. 2015;55(2):131-137.

39. Panda B, Siller R, Panda A. Influenza vaccination during pregnancy and factors for lacking compliance with current CDC guidelines. J Matern Fetal Neonatal Med. 2011;24(3):402-406.

40. American Congress of Obstetrics and Gynecology (ACOG) Immunization Resources for Obstetricians and Gynecologists. A comprehensive toolkit. Available from: http://www.acog.org/Search?Keyword= pertussis+toolkit. Accessed August 31, 2015.
Vaccine: Development and Therapy

\section{Publish your work in this journal}

Vaccine: Development and Therapy is an international, peer-reviewed, open access journal that spans the spectrum of vaccine design and development through to clinical applications. The journal is characterized by the rapid reporting of application notes, reviews, original research and clinical studies in all therapeutic areas. Clinical outcomes, patient safety,
Dovepress

and programs for the development and effective, safe, and sustained use of vaccines will be a feature of the journal. The manuscript management system is completely online and includes a very quick and fair peer-review system. Visit http://www.dovepress.com/testimonials.php to read real quotes from published authors. 